\title{
THEORY OF PLANNED BEHAVIOR TERHADAP KINERJA MAHASISWA DENGAN MIND MAPPING SEBAGAI MEDIASI
}

\author{
Tri Danarti ${ }^{1}$, Sentot Imam Wahjono ${ }^{2}$, Siti Salbiyah $^{3}$ \\ ${ }^{1)}$ Fakultas Ekonomi dan Bisnis Universitas Muhammadiyah Surabaya
}

\begin{abstract}
This study aims to determine the positive and significant effect of Theory of Planned Behavior on Student Performance directly and the effect of Theory of Planned Behavior on Student Performance through Mind Mapping Mediation. This study uses a descriptive quantitative approach, with a population of two hundred and thirty-six students from Bureau data. Academic, University of Muhammadiyah Surabaya, Faculty of Economics and Business who have passed the introductory business course with Mind Mapping mediation and the samples taken are one hundred forty-two students. The results of this study are that there is a positive and significant influence of Theory of Planned Behavior on the performance of students of the Faculty of Economics and Business, Muhammaiyah University Surabaya through Mind Mapping mediation.
\end{abstract}

Keywords : Theory of Planned Behavior; Mind Mapping; Introduction to Business Correspondence to : tridanarti0@gmail.com

\begin{abstract}
ABSTRAK
Penelitian ini bertujuan untuk mengetahui pengaruh positif dan signifikan dari Theory of Planned Behavior terhadap Kinerja mahasiswa secara langsung dan pengaruh Theory of Planned Behavior terhadap Kinerja mahasiswa melalui Mediasi Mind Mapping. Penelitian ini menggunakan pendekatan kuantitatif deskriptif, dengan populasi dua ratus tiga puluh enam mahasiswa dari data Biro Akademisi Universitas Muhammadiyah Surabaya Fakultas Ekonomi dan Bisnis yang telah lulus mata kuliah pengantar bisnis dengan mediasi Mind Mapping dan sampel yang diambil sebanyak seratus empat puluh dua mahasiswa. Hasil penelitian ini adalah terdapat pengaruh yang positif dan signifikan antara Theory of Planned Behavior terhadap Kinerja Mahasiswa Fakultas Ekonomi dan Bisnis Universitas Muhammadiyah Surabaya melalui mediasi Mind Mapping. Sehingga rekomendasinya diharapkan untuk menyelenggarakan program pembelajaran dengan menggunakan metode mind mapping agar mahasiswa lebih mudah memahami pembelajaran.
\end{abstract}

Kata Kunci : Theory of Planned Behavior; Mind Mapping; Pengantar Bisnis

\section{Riwayat Artikel:}

Received: 23 Desember 2020

Revised: 13 Januari 2021

Accepted: 25 Januari 2021 


\section{PENDAHULUAN}

Belajar adalah proses yang dilakukan seumur hidup. Belajar berkelanjutan dapat menambah pengetahuan yang lebih banyak, pemahamannya lebih luas dan berwawasan yang lebih baik tentang kehidupan akan menjadikan seseorang yang lebih baik, bertanggung jawab dan menjadi warga negara yang jujur. Dalam proses pembelajaran, siswa adalah pusat pendidikan (Lumpkin,2007). Dalam pembelajaran pengantar bisnis merupakan salah satu mata kuliah yang memberikan pemahaman kepada mahasiswa tentang bagaimana suatu organisasi bisnis sehingga mencapai tujuannya. Dengan pembelajaran Pengantar Bisnis diharapkan mahasiswa dapat memahami bagaimana menjadi wirausaha, dan mendapatkan manfaat dari kemajuan teknologi dan informasi untuk menjadi organisasi bisnis yang lebih unggul. (Edwards \& Cooper, 2010)

Salah satu kesulitan mahasiswa dalam menguasai materi kuliah Pengantar Bisnis antara lain karena materinya hanya bisa dipahami dengan membaca. Bukan hal yang mudah bagi mahasiswa yang tidak suka membaca untuk memahami materi tersebut. Agar mahasiswa dapat menguasai materi kuliah, salah satunya cara yang dilakukan oleh dosen adalah memberikan tugas membuat RKM (Ringkasan Materi kuliah). Menurut Buzan (2007), cara mencatat RKM menghasilkan catatan kuliah yang monoton karena semua ringkasan mata kuliah apapun akan ditulis dengan cara yang sama yaitu menggunakan kertas bergaris dan ditulis bergerak dari kiri ke kanan. (Buran \& Filyukov, 2015)menawarkan cara lain untuk membuat catatan kuliah yaitu dengan menggunakan teknik Mind Map. Menurut Buzan (2005: 12) menyatakan bahwa Mind Map merupakan Teknik yang memungkinkan untuk berimajinasi dalam mengeksplorasi hubungan antar konsep dalam pembelajaran serta dapat membatu kerja otak dalam pengambilan data dan penyimpanan data yang memiliki akses untuk perpustakaan raksasa dalam otak.
Beberapa penelitian menunjukkan bahwa teknik mind map telah digunakan dalam berbagai pembelajaran disiplin ilmu, seperti pada imu psikologi, ilmu matematika dan akuntansi (Fun dan Maskat, 2010), penggunaan mind map oleh siswa SMA (Ardiyanti, 2016). Penelitian tersebut berfokus pada efektivitas penggunan mind map untuk menghasilkan kemampuan secara akademis. Penelitian ini mencoba menjelaskan kinerja mahasiswa dengan dimediasi oleh Mind Map dalam pembelajaran Pengantar Bisnis berdasarkan Theory of Planned Behavior. Menurut Ajzen (1991), "Niat seseorang dilakukan oleh tiga konstruk yaitu Attitude Toward Behavior (Sikap terhadap perilaku), Subjective Norm (Norma subjektif) dan Perceived Behavioral Control (Kontrol perilaku persepsian)". TPB sangat sesuai untuk digunakan dalam menjelaskan berbagai perilaku kewirausahaan dan cocok untuk menjelaskan perilaku apapun yang memerlukan perencanaan.(Cruz et al., 2015)

Dalam proses pembelajaran berlangsung banyak mahasiswa yang kurang memperhatikan penjelasan dosen, hal tersebut tampak jelas ketika dosen memberikan pertanyaan namun mahasiswa tidak bisa menjawab. Mereka sibuk dengan kegiatan masing-masing, ada juga mahasiswa yang mengobrol dengan teman lainnya, melamun, ada yang mendengarkan tetapi tampak lesu, bahkan ada yang bermain handphone. Sebagian besar mahasiswa malas untuk bertanya yang baru dijelaskan oleh dosen. Sedangkan dalam kinerja mahasiswa sangat lambat bisa dilihat dari waktu pengumpulan tugas, yang seharusnya dikumpulkan jam 09.00 masih ada juga yang mengumpulkan lebih dari batas waktu yang ditentukan. Dilihat dari permasalahan tersebut peneliti ingin melakukan penelitian dengan inovasi yang baru yaitu dalam pembelajaran yang menggunakan metode Mind Map. (Crowe \& Sheppard, 2012) Sehingga guna meningkatkan daya faham dan daya ingat serta motivasi belajar lebih meningkat dan mahasiswa menjadi lebih kreatif yang 
diharapkan dari penerapan mind map saat pembelajaran. (van Holm, 2017)

Universitas Muhammadiyah Surabaya merupakan satu-satunya Universitas Muhammadiyah yang berada di Surabaya yang didirikan pada tanggal 5 Desember 1981, yang terletak di Jalan Sutorejo No. 59 Surabaya, Jawa Timur. Universitas Muhammadiyah Surabaya memiliki delapan fakultas dan/atau dua puluh delapan program studi, salah satunya Fakultas Ekonomi dan Bisnis dengan dua program studi yaitu Program Studi Manajemen dan Akuntansi. Pada Fakultas Ekonomi dan Bisnis terdapat sebuah ide baru dalam proses pembelajaran. Ide baru ini di rancang dengan menggunakan Mind Map. Dalam inovasi pembelajaran Mind Map diharapkan dapat berpengaruh terhadap kinerja mahasiswa dalam belajar Pengantar Bisnis di semester satu. Berdasarkan atas uraian latar belakang, peneliti ingin mengetahui apakah Theory of Planned Behavior dapat berpengaruh terhadap kinerja mahasiswa melalui mediasi Mind Map dalam mata kuliah Pengantar Bisnis.

\section{METODE PENELITIAN}

Pada penelitian ini, pendekatan kuantitatif deskriptif. Mahasiswa yang telah lulus mata kuliah Pengantar Bisnis dengan media pembelajaran Mind Map Fakultas Ekonomi dan Bisnis di Universitas Muhammadiyah Surabaya sebagai populasi yang berjumlah 236 mahasiswa dan diambil sampel sebanyah 142 mahasiswa. Pada penelitan ini terdapat tiga variabel yakni variabel independent yaitu Theory of Planned Behavior yang terdiri dari sikap, norma subjektif dan kontrol perilaku. Sedangkan untuk variabel dependent yakni kinerja mahasiswa dan mind mapping sebagai variabel mediasinya. Instrumen yang digunakan peneliti mengambil reerensi dari penelitian terdahulu yang kemudian di uji tingkat validitas dan reliabilitas. Untuk penyebaran kuesionernya dilakukan dengan sistem online menggunakan google form kemudian hasilnya diolah dalam aplikasi SPSS. Penganalisisan data penulis menggunakan uji parsial (uji t) untuk menentukan hipotesis diterima atau ditolak dengan cara melihat nilai signifikan $<0,05 \%$. Analisis regresi linier sederhana dan analisis lajur juga digunakan dalam penelitian ini. Analisis Jalur tujuannya untuk menjelaskan hubungan variabel Theory of Planned Behavior (X) terhadap kinerja Mahasiswa (Y) dimediasi Mind Mapping (Z). Untuk mengetahui pengaruh mediasi yang ditunjukkan oleh perkalian keofisien signifikan atau tidak maka akan dilakukan uji sobel, uji sobel dilakukan dengan cara:

Hitung standar error dari koefisien indircet effect $(\mathrm{Sp} 2 \mathrm{p} 3)$ dengan rumus:

Sp2p3 $=\sqrt{p 3^{2} S p 2^{2}+p 2^{2} S p 3^{2}+S p 2^{2} S p 3^{2}}$

(Ghozali, 2011:255)

Berdasarkan hasil perhitungan dari Sp2p3, maka dapat dihitung nilai t statistik pengaruh mediasi dengan rumus: $t=p 2 p 3 S p 2 p 3$ (Ghozali,2011: 255)

Jika nilai t hitung lebih besar di bandingkan nilai t tabel maka dapat disimpulkan bahwa mediasi terdapat pengaruh yang signifikan.

\section{HASIL PENELITIAN}

Data responden terdiridari 85 mahasiswa berjenis kelamin perempuan dan 57 mahasiswa berjenis kelamin laki-laki. Data Usia responden diperoleh untuk usia $<20$ tahun yaitu 21 mahasiswa atau 14, 5\%, untuk responden antara usia 21- 30 tahun adalah 115 orang atau $81,4 \%$, kemudian untuk responden usia antara 31- 40 tahun sebanyak 6 mahasiswa atau 4, $1 \%$. Sedangkan responden yang usia antara 40- 41 tahun dan yang lebih dari 40 tahun yaitu 0 (nol). Pendidikan terakhir responden pada jenjang SMA/SMK terdapat 121 mahasiswa atau $85,5 \%$, kemudian pada jenjang D3 terdapat 17 mahasiswa atau $11,7 \%$ dan pada jenjang $\mathrm{S} 1$ berjumlah 4 mahasiswa atau 2,8\%, sedangkan pada jenjang S2 dan S3 adalah 0 (nol). Sedangkan data responden yang Sudah Lulus Mata Kuliah Pengantar Bisnis adalah $100 \%$ lulus.

Berdasarkan data untuk variabel Theory of Planned Behavior (X), Kinerja 
Mahasiswa (Y), dan Mind Mapping (Z) dari hasil kuesioner yang disebar ke 142 responden, maka dapat diketahui persentase skor dibawah ini:

TABEL 1: Persentase Skor Variabel

\begin{tabular}{llrl}
\hline No & Indikator $\mathbf{X}$ & $\boldsymbol{\Sigma}$ skor & \% skor \\
\hline 1 & Attitude (sikap) & 5.010 & $50,10 \%$ \\
\hline & $\begin{array}{l}\text { Subjektive norm } \\
\text { (Norma subjektif) }\end{array}$ & 1.692 & $16,92 \%$ \\
\hline & $\begin{array}{l}\text { Preceived Behavior } \\
\text { Control (kontrol } \\
\text { perilaku yang } \\
\text { dirasakan) }\end{array}$ & 2.923 & $29,23 \%$ \\
\hline Jumlah & 9.625 & $96,25 \%$ \\
\hline No & Indikator Y & $\mathbf{\Sigma}$ skor & \% skor \\
\hline 1 & Kinerja mahasiswa & 4.264 & $42,64 \%$ \\
\hline Jumlah & 4.264 & $42,64 \%$ \\
\hline No & Indikator Z & $\mathbf{\Sigma}$ skor & $\%$ skor \\
\hline 1 & Mind Mapping & 6.106 & $61,06 \%$ \\
\hline Jumlah & 6.106 & $61,06 \%$ \\
\hline
\end{tabular}

Hasil pada tabel diatas menunjukkan bahwa mahasiswa memberikan kontribusi sangat setuju, netral dan setuju terhadap masing-masing variabel.

Pengujian hipotesis yang dilakukan untuk uji validitas ataupun reliabilitas diperoleh hasil yang valid dan reliabel karena tingkat sig $<0.05 \%$ dan tingkat reliabel $<0,06 \%$. Uji t (Uji Parsial), Uji t (Parsial) dalam Pengaruh Theory of Planned Behavior (X) terhadap Kinerja Mahasiswa (Y) menunjukkan bahwa nilai Theory of Planned Behavior (X) adalah $0,000<0,05$, jadi disimpulkan bahwa adanya pengaruh signifikan Theory of Planned Behavior (X) terhadap kinerja mahasiswa (Y). Sedangkan uji $t$ dalam Pengaruh Theory of Planned Behavior (X) dan Kinerja Mahasiswa (Y) terhadap Mind Mapping (Z) menunjukan terdapat pengaruh signifikan Theory of Planned Behavior dan kinerja mahasiswa terhadap mind mapping yang mana nilai signifikan menunjukan $<0,05$.

Analisis Regresi Linier Sederhana, koefisien regresi $\mathrm{X}$ sebesar 0,176 berarti setiap penambahan nilai $1 \%$ dari $\mathrm{X}$, maka nilai partisipasi bertambah 0,176 . Koefisien regresi tersebut bernilai positif, sehingga dapat dikatakan bahwa arah pengaruh variabel Theory of Planned Behavior terhadap Kinerja Mahasiswa adalah positif.Berdasarkan nilai signifikan dihasilkan sebesar $0,000<0,05$, bahwa variabel Theory of Planned Behavior (X) berpengaruh terhadap Kinerja Mahasiswa (Y).

Analisis Jalur (Path Analysis) menghasilkan analisis pengaruh $\mathrm{X}$ melalui $\mathrm{Z}$ terhadap $X$, diketahui pengaruh langsung diberikan $\mathrm{X}$ terhadap $\mathrm{Y}$ sebesar 0, 232. Sedangkan pengaruh tidak langsung $X$ melalui $\mathrm{Z}$ terhadap $\mathrm{Y}$ yaitu perkalian antara nilai beta $X$ terhadap $Y$ yaitu: $0,232 \times 0,586=$ 0,135 . Maka pengaruh total yang diberikan $X$ terhadap $\mathrm{Z}$ yakni pengaruh langsung ditambah dengan pengaruh tidak langsung adalah $0,232+0,135=0,367$. Demikian hasil perhitungan diatas diketahui bahwa nilai pengaruh langsung sebesar 0,232 dan pengaruh tidak langsung sebesar 0,135 yang dapat diartikan bahwa nilai pengaruh tidak langsung lebih besar dari pada pengaruh langsung, hal ini menunjukkan bahwa secara tidak langsung $\mathrm{X}$ melalui $\mathrm{Z}$ mempunyai pengaruh signifikan terhadap $\mathrm{Y}$ diterima.

Dari perhitungan uji sobel dapat disimpulkan bahwa nilai Sp2p3 sebesar 0, $179<0,05$ maka dapat dikatakan bahwa koefisien mediasi signifikan, sehingga diartikan bawha adanya pengaruh mediasi Mind Mapping $(\mathrm{Z})$ dalam memediasi Theory of Planned Behavior (X) terhadap Kinerja Mahasiswa (Y).

TABEL 2: Pengujian Hipotesis

\begin{tabular}{|c|c|}
\hline Pengaruh langsung & $\begin{array}{l}\text { Pengaruh tidak } \\
\text { langsung }\end{array}$ \\
\hline \multirow{6}{*}{ 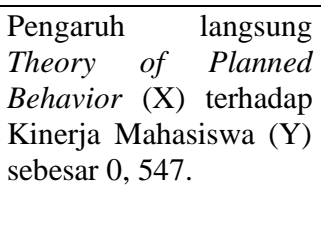 } & Pengaruh tidak \\
\hline & Theory of \\
\hline & Planned Behavior (X) \\
\hline & terhadap $\quad$ Kinerja \\
\hline & Mahasiswa (Y) Melalui \\
\hline & $\begin{array}{l}\text { Mind Mapping }(\mathrm{Z}) \\
\text { Sebesar } 0,320 .\end{array}$ \\
\hline
\end{tabular}

Sumber: Hasil Olahan SPSS 20, 2020

Berdasarkan tabel diatas dapat diartikan bahwa nilai pengaruh tidak langsung lebih besar dari pada pengaruh langsung, hal ini menunjukkan bahwa secara 
tidak langsung $\mathrm{X}$ melalui $\mathrm{Z}$ mempunyai pengaruh signifikan terhadap $\mathrm{Y}$ diterima.

\section{PEMBAHASAN}

Pengaruh Theory of Planned Behaviour (X) berpengaruh terhadap variabel kinerja mahasiswa secara langsung sebesar 0 , 232 dengan arah yang positif, dimana hubungan tersebut terbukti bahwa Theory Of Planned Behaviour (X) berpengaruh signifikan terhadap kinerja mahasiswa. Berdasarkan analisis jalur bahwa Theory of Planned Behaviour (X) berpengaruh langsung terhadap Kinerja Mahasiswa (Y) sebesar 0, 232. Sedangkan pengaruh tidak langsung Theory Of Planned Behaviour (X) melalui Kinerja Mahasiswa (Y) terhadap Mind Mapping ( $\mathrm{Z})$ yaitu 0, 135. Maka pengaruh total yang diberikan $\mathrm{X}$ terhadap $\mathrm{Z}$ yakni pengaruh langsung adalah 0, 367. Demikian hasil perhitungan diatas diketahui bahwa nilai pengaruh langsung sebesar 0,232 dan pengaruh tidak langsung sebesar 0,135 yang dapat diartikan bahwa nilai pengaruh tidak langsung lebih besar dari pada pengaruh langsung, hal ini menunjukkan bahwa secara tidak langsung $\mathrm{X}$ melalui $\mathrm{Y}$ mempunyai pengaruh signifikan terhadap $\mathrm{Z}$.

Maka terdapat kesamaan hasil penelitian dari jurnal Yanto Darmawan dan (Srirejeki et al., 2017) yakni Theory of Planned Behaviour mempengaruhi kinerja mahasiswa pengauditan dalam membuat ringkasan materi kuliah berbentuk mind map. (Tsordia \& Papadimitriou, 2015) Dengan demikian hipotesis penelitian menyatakan bahwa "Terdapat pengaruh positif dan signifikan Theory of Planned Behaviour (X) terhadap Kinerja Mahasiswa (Y) melalui Mind Mapping $(\mathrm{Z})$ pada mahasiswa Fakultas Ekonomi dan Bisnis Universitas Muhammadiyah Surabaya" diterima.

\section{KESIMPULAN}

Dengan melihat hasil pembahasan masalah, maka kesimpulannya yaitu terdapat pengaruh positif dan signifikan Theory of Planned Behaviour terhadap Kinerja Mahasiswa Melalui Mind Mapping Fakultas
Ekonomi dan Bisnis di Universitas Muhammadiyah Surabaya. Sehingga rekomendasinya diharapkan untuk menyelenggarakan program pembelajaran dengan menggunakan metode mind mapping agar mahasiswa lebih mudah memahami pembelajaran

\section{DAFTAR PUSTAKA}

Ardiyanti, N. (2016). Pengaruh Penerapan Metode Mind Mapping Terhadap Hasil Belajar Siswa Pada Mata Pelajaran Akuntansi SMK Muhammadiyah 3 Singosari. In SKRIPSI Jurusan Akutansi - Fakultas Ekonomi UM.

Ajzen, I., 1991. The Theory of Planned Behavior: Organizational Behavior and Human Decision Processes. University of Massachusetts at Amherst. 50:179- 211.

Basir, Nurul Muniroh,. Wahjono, SI,. 2004. Jurnal Balance. The Effectiveness of Training Towards Jon Satisfaction with Job Performance As a Mediating Variabel at Agricultur Agency: Evidence From Malaysia. Universitas Muhammadiyah Surabaya. ISSN: 1693-9352 Vol. X, No. 19 pp. 51-61.

Buran, A., \& Filyukov, A. (2015). Mind Mapping Technique in Language Learning. Procedia - Social and Behavioral Sciences. https://doi.org/10.1016/j.sbspro.2015.10 .010

Crowe, M., \& Sheppard, L. (2012). Mind mapping research methods. Quality and Quantity. https://doi.org/10.1007/s11135-0119463-8

Cruz, L. da, Suprapti, N. W. S., \& Yasa, N. N. K. (2015). Aplikasi Theory Of Planned Behavior Dalam Membangkitkan Niat Berwiraswasta Bagi Mahasiswa Fakultas Ekonomi Unpaz, Dili Timor Leste. E-Jurnal Ekonomi Dan Bisnis Universitas Udayana. 
Darmawan, Y, Sururi., 2016. Jurnal Ekonomi dan Bisnis. Faktor-Faktor Penentu Niat Mahasiswa Pengauditan Menggunakan Mind Map Untuk Meringkas Materi Kuliah: Aplikasi Theory Of Planned Behavior. Vol, 10, No. 2, Juli 2016

Edwards, S., \& Cooper, N. (2010). Mind mapping as a teaching resource. Clinical Teacher. https://doi.org/10.1111/j.1743498X.2010.00395.x

Fishbein, M., \& Ajzen, I,, 1975. Belief, Attitude, Intention, and Behavior: An Introduction to Theory and Research, Reading. MA: Addison-Wesley.

Ghozali, Imam., 2011. Aplikasi Analisis Multivatiatie dengan Program SPSS. Semarang: Badan Penerbit Universitas Diponegoro.

Grid, A., \& J, J, Bagraim., 2008. South African Journal of Psychology. The Theory Of Planned Behavior as Predictor of Entrepreneurial Intentamongst Final-year University Student

Hairunazri., 2015. Tesis. The Effective Method To Enchance Memorizing Skills In Microeconomics: Comperative Between MindMapping And Keyword Drawing Methods. Faculty of Technology Management and Technopreneurship. Universiti Teknikal Malaysia Melaka.

Ismal, V, Y., \& Zain, E., 2008. Peranan Sikap, Norma Subjektif, dan Perceived Behavior Control terhadap Intensi Pelajar SLTA untuk Memilih Fakultas Ekonomi. Jurnal Ekonomi dan Bisnis Vol. 5 No. 3, Desember 08 .

Li, Wei. 2006. Entrepreneurial Intention Among International Student: Testing a model of entrepreneural intention. Journal University of Illinois at Urbana - Champaign, 217721- 9969

Lumpkin, A., 2007. Caring teachers the key to student learning. Kappa Delta Pi
Record. Vol. 43, Issue 4, pp. 158160.

Srirejeki, K., Faturahman, A., \& Supeno, S. (2017). Perspektif Theory of Planned Behavior Kaitannya dengan Intensi Berwirausaha: Peran Gender sebagai Moderator. Jurnal Akuntansi Dan Bisnis.

https://doi.org/10.20961/jab.v17i1.215

Tsordia, C., \& Papadimitriou, D. (2015). The Role of Theory of Planned Behavior on Entrepreneurial Intention of Greek Business Students. International Journal of Synergy and Research. https://doi.org/10.17951/ijsr.2015.4.1.23

van Holm, E. J. (2017). Makerspaces and Local Economic Development. Economic Development Quarterly, 31(2), 164-173. https://doi.org/10.1177/0891242417690 604 